\title{
Visual pop-out in infants: Evidence for preattentive search in 3- and 4-month-olds
}

\author{
JOHN COLOMBO, JENNIFER S. RYTHER, JANET E. FRICK, and JENNIFER J. GIFFORD \\ University of Kansas, Lawrence, Kansas
}

\begin{abstract}
The present experiment tested for preattentive visual search in 3- and 4-month-old infants using stimulus features described by Treisman and Souther (1985) as producing visual "pop-out" effects in adults. Infants were presented with two visual arrays to the left and right of midline. One array comprised homogeneous elements, while the other had a discrepant element embedded in it. On the basis of previous research, we expected infants to fixate the array containing the embedded discrepant element. The pattern of fixation indicated detection of the embedded discrepant element for both age groups, but only with stimuli shown to elicit visual pop out in adults. This asymmetry in detection is consistent with the presence of preattentive visual search in infants as young as 3 months.
\end{abstract}

Visual search has been described in terms of a two-phase sequence (see Beck, 1982; Neisser, 1963; Treisman, 1988). The first, "preattentive" phase presumably segregates the visual field into discrete or separate regions or "objects" on the basis of differences in texture or luminance. The second, "attentive" phase involves a more effortful detailed visual inspection of the objects identified in the field by the preliminary preattentive scan.

Preattentive visual search has generally been documented through asymmetries in latencies to detect a discrepant element in visual arrays (Treisman \& Gormican, 1988; Treisman \& Souther, 1985). Preattentive search is only negligibly affected by the number of elements in the visual array (Treisman, 1988) and is thus believed to reflect a parallel search of the visual field (Julesz, 1984). Preattentive processing very much resembles "automatic" cognitive processes (Treisman, Vieira, \& Hayes, 1992); indeed, discriminations that are made in preattentive searches have been described as "jumping" or "popping out" of the visual display (Neisser, 1963) and have thus been termed "pop-out" effects. "Attentive" visual search, on the other hand, is typically characterized as serial in

This work was supported by NIH Grant HD29960-01. J.E.F. was supported in part by Grant HD07173-13. This program of research is also supported by the University of Kansas Mental Retardation Research Center. J.C. and J.S.R. share primary authorship. Portions of this research involving the 3-month-old age group were submitted by J.S.R. in partial fulfillment of the MA degree awarded by the Department of Human Development at the University of Kansas. The authors thank Sara Coleman, Sheila Gorman, Terrill Saxon, and Kim Stowe for their assistance in data collection and preparation. We are especially grateful to the staff of the University of Kansas Regents Center for their assistance and cooperation in our research and, as always, to the families who participated in these studies. A preliminary version of this paper was presented at the International Conference on Infant Studies, June 1994, in Paris, France. Address correspondence and requests for reprints to the authors at the Department of Human Development, 4001 Dole Human Development Center, University of Kansas, Lawrence, KS 66045-2133 (e-mail: colombo@kuhub.cc.ukans.edu). nature, and thus is considered to be a slower and more effortful endeavor.

Because of the robustness and seemingly fundamental nature of preattentive search and visual pop-out effects in adult vision (e.g., Hearst, 1991), pop-out effects might be expected to be manifest very early in life. Findings consistent with preattentive visual search and pop-out effects have recently been reported in 3-month-olds (RoveeCollier, Hankins, \& Bhatt, 1992). However, such effects were inferred from infants' patterns of long-term retention rather than from an actual visual search or perceptual task.

The present research was conducted to test young (3and 4-month-old) infants for visual search asymmetries that would indicate the presence of a preattentive phase. The goal was to test for a visual pop-out effect under conditions that more closely approximated the visual search tasks in which pop-out effects have been documented with adult subjects. To do this, infants were presented with pairs of visual arrays, one consisting of homogeneous elements and the other of the same elements with an embedded discrepancy. Furthermore, two sets of arrays that corresponded to feature-present versus feature-absent pop-out effects (see Treisman, 1988; Treisman \& Souther, 1985) were employed.

Previous research (e.g., Colombo, Laurie, Martelli, \& Hartig, 1984; Van Giffen \& Haith, 1984) had suggested that, when presented with visual arrays in which a discrepancy is embedded, infants of these ages will fixate more toward the discrepancy than toward areas of homogeneity. We expected that if infants could detect the discrepancies embedded within the arrays used here, they would look longer toward the array containing the discrepancy than toward the homogeneous array. Furthermore, if infants showed the asymmetry in detection that characterizes the pop-out effect in adults, we expected that this discriminative response would be more prevalent in the feature-present condition than in the feature- 
absent condition. Given the fact that infants were tested for their detection of discrepant elements embedded in arrays under relatively severe time constraints (i.e., $5 \mathrm{sec}$ per trial), such performance would be indicative of a visual pop-out effect and, thus, of the presence of the preattentive visual search described by Treisman (e.g., 1988 ) in adults.

\section{METHOD}

\section{Subjects}

A total of 100 full-term, healthy infants (55 3-month-olds, and 45 4-month-olds) were recruited by mail and telephone from the middleclass suburbs of metropolitan Kansas City. Of this sample, 36 infants (23 3-month-olds and 134 -month-olds) were excluded from final analyses for reasons of fussiness $(n=20)$, sleepiness $(n=2)$, parental interference (i.e., disrupting of infants' fixations by laughing or talking while the search task was being conducted; $n=3$ ), looking to only one lateral position throughout the visual search task $(n=7)$, or experimenter error/equipment failure $(n=4)$. The final sample included a total of 64 infants, with 32 from each age group.

\section{Stimuli}

To begin the session, a black-and-white picture of a female face was used as a warm-up slide. The stimuli used in the visual search task were constructed of feature-positive (FP) and feature-absent (FA) arrays similar to those shown in Treisman and Souther (1985). Detection of the discrepant element in the FP array has been reported to "pop out" for adults; it is thus inferred that, in adults, this detection is accomplished through a preattentive, parallel search. Detection of the discrepant element in the FA array, however, is apparently accomplished through an attentive, serial visual search. Each of the FA and FP arrays was paired with a corresponding homogeneous array in which no discrepant element was embedded. The dispersement of the elements in all of the arrays used was identical, as was the locus of the discrepancy in the nonhomogeneous arrays. When projected, the arrays subtended a total visual angle of $33^{\circ}$ high $\times 24^{\circ}$ wide and the individual circular elements that comprised the arrays subtended a visual angle of approximately $5^{\circ}$. The four arrays employed in the study are shown in their respective pairings in Figure 1.

\section{Design and Procedure}

To begin the session, the black-and-white slide of the female face was projected in the center of the screen for $20-30 \mathrm{sec}$. The visual search task, which immediately followed this presentation, consisted of four blocks of two trials each, in which the paired arrays shown in Figure 1 were presented to the left and right of the infant's midline, separated by a visual angle of $30^{\circ}$.

Across the four blocks, the two tasks (FP or FA) were shown for two blocks each. The presentation order of the two tasks was varied between infants, with half the infants receiving trial-block tasks in the order FA-FP-FP-FA and the other half receiving tasks in the order FPFA-FA-FP. The two trials within each block involved the same search task (i.e., FP or FA), but the lateral positions of the two arrays were reversed in the second trial of the block relative to the first. This was necessary because some infants show a bias for fixating particular lateral positions at these ages (Cohen \& Gelber, 1975); by testing both array pairs at both positions within a block, data collapsed across the two trials within a block were free from the influence of lateral bias, and could be validly compared with an a priori chance level of $50 \%$. Each trial lasted until the infant had accumulated $5 \mathrm{sec}$ of total fixation of the arrays presented; that is, infants had to look for a total of $5 \mathrm{sec}$ before the trial was ended. Examples of testing sequences for both presentation orders are shown in Table 1.

\section{Apparatus}

All infants were tested in a darkened $3 \times 3 \mathrm{~m}$ room with black walls and ceiling. The infants were seated in a Fisher-Price car seat situated
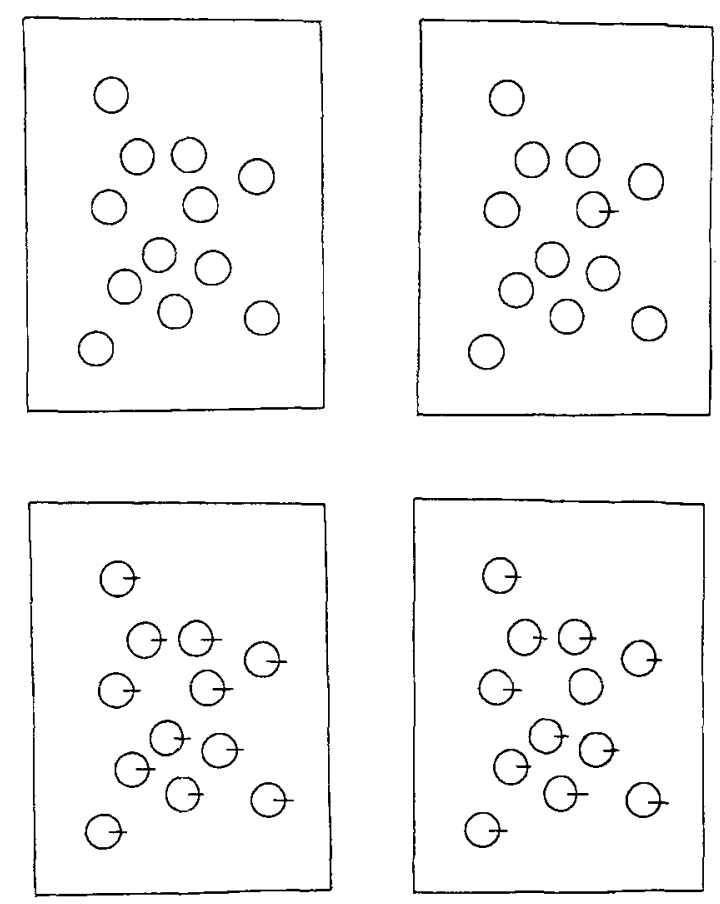

Figure 1. Stimuli used in the visual search task. The top panel represents the array pairs used for the feature-positive (FP) task, which produces a preattentive "pop out" for adults. The bottom panel represents the array pairs used for the feature-absent (FA) task, in which the discrepant element can be detected only through a serial, attentive search. Homogeneous arrays are to the left in each panel.

$38 \mathrm{~cm}$ from a $79 \times 73 \mathrm{~cm}$ rear-projection screen. The stimuli were rearprojected onto the screen by three Kodak Carousel projectors.

A video camera was mounted at the bottom of the screen. The output of this camera was sent to a VCR in another room, where the infant's visual fixations of the stimuli were recorded and also played "live" to a monitor. An observer who was blind to the position and identity of the stimuli coded the direction and duration of the infant's fixations as they occurred, using pushbuttons interfaced with a Zenith Z-159 microcomputer. The recorded image of the infant's fixations was then replayed for purposes of calculating reliability on the live observations. Interobserver reliability was obtained on $58 \%$ of the completed sessions; Pearson correlations of the two observers' coding of the percent of infants' fixations to the array containing the discrepant element averaged +.97

\section{RESULTS}

A mixed-design analysis of variance (ANOVA) involving the between-subject factors of order (2) and age (2) and the within-subject factors of block (2) and task (2) was performed on infants' percent preferences for the visual array containing the discrepant element. The only significant term to emerge from this analysis was a main effect for task $[F(1,60)=6.54, p=.013]$. The percent time that infants spent fixating the FA array with the discrepancy embedded was $49.3 \%(S D=12.2)$, while the percent time that infants spent fixating the FP array with the embedded discrepancy was $55.4 \%(S D=16.1)$. 
Table 1

Examples of Typical Testing Sequences for the Visual Search Tasks

\begin{tabular}{|c|c|c|c|c|}
\hline \multirow{2}{*}{$\frac{\text { Order }}{1}$} & \multirow{2}{*}{$\frac{\text { Task Block }}{\mathrm{FA}_{1}}$} & Trial & \multicolumn{2}{|c|}{$\begin{array}{l}\text { Homogenous } \\
\text { Array on: }\end{array}$} \\
\hline & & & L & $R$ \\
\hline \multirow{7}{*}{2} & $F P_{1}$ & 34 & $\mathrm{R}$ & L \\
\hline & $\mathrm{FP}_{2}$ & 56 & L & $\mathbf{R}$ \\
\hline & $\mathrm{FA}_{2}$ & 78 & $\mathbf{R}$ & $\mathrm{L}$ \\
\hline & $\mathrm{FP}_{1}$ & 12 & $\mathbf{R}$ & $\mathrm{L}$ \\
\hline & $F A_{1}$ & 34 & L & $\mathbf{R}$ \\
\hline & $\mathrm{FA}_{2}$ & 56 & $\mathrm{R}$ & $\mathrm{L}$ \\
\hline & $\mathrm{FP}_{2}$ & 78 & L & $\mathbf{R}$ \\
\hline
\end{tabular}

Note-FA $=$ feature absent, $F P=$ feature present. $L=$ left (homogenous array presented to the right of infant's midline), $R=$ right.

Thus, infants looked significantly more to the discrepant array in the FP condition than in the FA condition.

Although the ANOVA indicated that the infants' task performance was significantly different as a function of the type of task involved, it did not address the issue of whether such performance was significantly different from random responding. This was tested by conducting $t$ tests of each of these percentages against chance levels $(50 \%)$. The infants' fixation of the discrepant array on the FA task was not different from chance $[t(63)=0.48$, n.s.]; however, infants' fixation of the discrepant array on the FP task significantly exceeded chance levels $[t(63)=2.68, p=.009]$. The distribution of infants' responses under both of these conditions was unimodal.

\section{DISCUSSION}

The results presented here are clearly consistent with a "pop-out" effect for FP stimuli in 3-and 4-month-old infants, similar to that reported by Treisman and Souther (1985) for adults. Although the present study did not vary the locus of the discrepant element within the arrays, the absence of any main effect or interaction involving trial block indicates that the observed effect was not due to the infants' learning where to look in the array across trials.

This finding further reinforces the observations from long-term retention paradigms, whose findings are concordant with the existence of visual popout effects in infancy (Rovee-Collier et al., 1992), and directly suggests that preattentive search is present at this age. The findings from this study are especially compelling, because they are derived from a paradigm in which the assessment of infants' visual search closely resembles the kinds of search tasks used with adult subjects. As such, this finding is consistent with the seemingly fundamental nature of pop-out effects within the adult visual system (e.g., Treisman \& Gormican, 1988).

At the same time, we note that the pop-out effect reported here with infants is not as striking as that seen with adult subjects, nor is the size of the effect as strong as is sometimes observed with infants in selectivelooking paradigms. This may reflect limitations of infant visual search, the methodology used to assess it, or differences in the size of pop-out effects between infant and adult subjects. All of these possibilities constitute appropriate topics for further inquiry.

Although the asymmetry of visual detection reported here is consistent with the existence of visual pop-out and preattentive search during infancy, this study represents only an initial foray into the area, and further empirical work is obviously in order. First of all, we assessed visual pop out with only one of a number of different types of displays that elicit similar preattentive detection effects in adults; future research with infant populations might be directed toward the use of color, texture, and other manipulations that yield such effects. Furthermore, one of the hallmarks of the parallel visual search that presumably gives rise to the visual pop-out effect is the fact that the preattentive detection of discrepancies in the visual field does not vary as a function of the number of elements in the visual array; future work should explore whether this is the case with infant subjects as well as with adults.

The presence of preattentive parallel visual search in 3- and 4. month-old infants, as suggested by these findings, raises a number of interesting questions bearing on the general domain of perceptual development. For example, it is logical to ponder how early such visual search is present in the human, if it is not a component of visual search at birth. Indeed, previous data on infants' detection of regional discrepancies in arrays suggest that pop-out-like effects may not be readily observed with 2-month-olds (see, e.g., Salapatek, 1975, especially pp. 212226), and that visual search in young infants may thus more closely resemble a serial, rather than a parallel, process. An emphasis on serial analysis in early infancy followed by an emergence of parallel visual search at about 3-4 months would be in general accord with $\mathrm{Co}$ hen's (e.g., 1988) hypotheses regarding visual information processing in infancy, in which infants under the age of 3 months are thought to engage primarily in a visual analysis based on lower order stimulus features, while infants older than 3 months of age are thought to focus primarily on the higher order, configural aspects of stimuli that are connoted by the interrelations of those features.

In addition to documenting a widely established adult visual effect in 3-and 4-month-old infants, it is hoped that the present report suggests that the investigation of current topics in adult visual perception and cognition is, in fact, feasible with even the most developmentally "difficult" populations. Such work has the potential for contributing to both the adult and the developmental literatures.

\section{REFERENCES}

BECK, J. (1982). Texture segmentation. In J. Beck (Ed.), Organization and representation in perception (pp. 285-317). Hillsdale, NJ: Erlbaum.

COHEN, L. B. (1988). An information-processing approach to infant cognitive development. In L. Weiskrantz (Ed.), Thought without language (pp. 211-228). Oxford: Oxford University Press, Clarendon Press.

COHEN, L. B., \& GELBER, E. (1975). Infant visual memory. In L. Cohen \& P. Salapatek (Eds.), Infant perception: From sensation to cognition (Vol. 1, pp. 347-404). New York: Academic Press

Colombo, J., Laurie, C. A., Martelli, T. A., \& Hartig, B. R. (1984). Stimulus context and infant orientation discrimination. Journal of Experimental Child Psychology, 37, 576-586.

HeArst, E. (1991). Psychology and nothing. American Scientist, 70, 432-433.

JuLESZ, B. (1984). Toward an axiomatic theory of preattentive vision. In G. M. Edelman, W. E. Gail, \& W. M. Cowan (Eds.), Dynamic aspects of neocortical function (pp. 585-612). New York: Wiley.

NEISSER, U. (1963). Visual search. Scientific American, 210(6), 94102.

Rovee-Collier, C. K., Hankins, E., \& BhatT, R. (1992). Textons, visual pop-out effects, and object recognition in infancy. Journal of Experimental Psychology: General, 121, 435-445.

SalapateK, P. S. (1975). Pattern perception in early infancy. In L. Cohen \& P. Salapatek (Eds.), Infant perception: From sensation to cognition (Vol. 1, pp. 133-248). New York: Academic Press.

Treisman, A. (1988). Features and objects: The Fourteenth Bartlett Memorial Lecture. Quarterly Journal of Experimental Psychology, 40A, 201-237.

Treisman A., \& Gormican, S. (1988). Feature analysis in early vision: Evidence from search asymmetries. Psychological Review, 95, 15-48.

Treisman A., \& Souther, J. (1985). Search asymmetry: A diagnostic for preattentive processing of separable features. Journal of Experimental Psychology: General, 114, 285-310.

Treisman, A., VIEIRA, A., \& HaYes, A. (1992). Automaticity and preattentive processing. American Journal of Psychology, 105, 341-362.

VAN GIFFEN, K., \& HAITH, M. M. (1984). Infant visual responses to gestalt geometric forms. Infant Behavior and Development, 7, 335346.

(Manuscript received July 22, 1994;

revision accepted for publication December $8,1994$. 